\title{
Critically Ill Cancer Patients: Issues in Management of Acute Respiratory Failure
}

\author{
Zuhair Alzibair* \\ Department of Medical Oncology, King Abdullah Medical City, Saudi Arabia
}

Submission: March 24, 2018; Published: March 29, 2018

"Correspondence Address: Zuhair Alzibair, Department of Medical Oncology, King Abdullah Medical City, Saudi Arabia, Email: abuzoooz60@gmail.com

\section{Objectives}

Cancer incidence has increased over the last few decades [1] On the other hand there is improvement in survival of patients with several types of solid tumors due to new advances in cancer therapy. As consequence there is increase in number of cancer patients who develop respiratory complications either due to the aggressive manifestations of their disease or the side effects of the treatment (.e.g. neutropenic infections, antineoplastic drugs related pneumonitis). Acute respiratory failure one of the main reasons for admitting cancer patients to intensive care units [2] It is a dilemma weather that every critically sick cancer patient has to be admitted to ICU. Although the problem is worldwide; this issue looks more complicated in health facilities that have limited resources.

\section{Methods}

To review the current standards of diagnosis and management of acute respiratory failure in cancer patients, a methodological literature pub med search was conducted. Used key words were: cancer patients, oncology patients, acute respiratory failure, intensive care units and critical illness.

\section{Results}

There are available recommendations outlines for management of respiratory failure in critically cancer a patients [3-5]. Special consideration should be given to cancer patients while applying assessment tools for ICU admission. APACHE II, SAPS II and SOFA are the most relevant scores for assessing critically ill cancer patients [6]. The mortality of cancer patients admitted to ICU with acute respiratory failure remains high (around 50\%-60\%) [2,7], so that early detection and proper management of respiratory complications by the primary physicians (oncologists/ internists) is of paramount. The decision of DNR (do not resuscitate) should be taken earlier for appropriate patients with advanced cancer by the primary treating oncologists to avoid unnecessary ICU admissions. In case of any unexpected or sudden deterioration in full code patients, the prognosis associated with the etiology of the acute respiratory failure, in the context of life expectancy from the underlying malignancy should be discussed before or soon after admission to the ICU $[8,9]$.

\section{Conclusion}

Multidisciplinary team approach is essential in treating critically ill cancer patients with acute respiratory failure. Although the discussion of the prognosis of cancer is very important, however malignancy/metastatic cancer itself should not be seen alone as an exclusion criterion for ICU admissions. Planned ceiling of care and addressing DNR status at appropriate time may help avoiding prolongation of suffering in patients with advanced cancer presenting with acute respiratory failure.

\section{References}

1. Ferlay J, Soerjomataram I, Dikshit R, Eser S, Mathers C, et al. (2015) Cancer incidence and mortality worldwide: Sources, methods and major patterns in GLOBOCAN 2012. Int J Cancer 136(5): 2015.

2. HMJ, Tabak J, Baier H (1982) Survival of patients with cancer in a medical critical care unit. Arch Intern Med 142(3): 527-529.

3. Pastores SM (2001) Acute respiratory failure in critically ill patients with cancer. Diagnosis and management. Crit Care Clin 17(3): 623-646.

4. Azoulay E (2014) On behalf of the Groupe de Recherche en RÃ, and animation Onco-HÃ, A New Standard of Care for Critically Ill Patients With Cancer.

5. Schellongowski P, Sperr WR, Wohlfarth P, Knoebl P, Rabitsch W, et al. (2016) Critically ill patients with cancer: chances and limitations of intensive care medicine-a narrative review. ESMO Open 1(5): e000018.

6. Kopterides P, Liberopoulos P, Ilias I, Anthi A, Pragkastis D, et al. (2011) General Prognostic Scores in Outcome Prediction for Cancer Patients Admitted to the Intensive Care Unit. Am J Crit Care 20(1): 56-66.

7. Staudinger T, Stoiser B, Müllner M, Locker GJ, Laczika K, et al. (2000) Outcome and prognostic factors in critically ill cancer patients admitted to the intensive care unit. Crit Care Med 28(5): 1322-1328.

8. Biskup E, Cai F, Vetter M, Marsch S (2017) Oncological patients in the intensive care unit: prognosis, decision-making, therapies and end-oflife care. Swiss Med Wkly 147(3132): 1-9.

9. Sihra L, Harris M, Reardon CO (2011) Using the Improving Palliative Care in the Intensive Care Unit (IPAL-ICU) Project to Promote Palliative Care Consultation. J Pain Symptom Manage 42(5): 672-675. 
CC) 1 BY $\begin{aligned} & \text { This work is licensed under Creative } \\ & \text { Commons Attribution } 4.0 \text { License }\end{aligned}$ 